Pure Appl. Chem., Vol. 72, No. 9, pp. 1623-1629, 2000.

(C) 2000 IUPAC

\title{
Stereoselective C,C-bond formation. Cyclizations of biradicals*
}

\author{
Bernd Giese $†$, Frédérique Barbosa, Christian Stähelin, \\ Stefan Sauer, Philipp Wettstein, and Caroline Wyss \\ Department of Chemistry, University of Basel, St. Johanns Ring 19, \\ $\mathrm{CH}-4056$ Basel, Switzerland
}

Abstract: The formation of C,C-bonds via photolytically generated biradicals can occur with high stereoselectivity. If triplet biradicals are involved, chiral induction is highly likely. Syntheses that occur only via singlet biradicals have a good chance to show a memory effect of chirality.

It has been known for about 20 years that radicals are versatile intermediates in organic synthesis [1], and 5-10 years ago it became clear that the rules for stereoselectivity can be applied also for reactions between radicals and nonradicals (Fig. 1) [2].
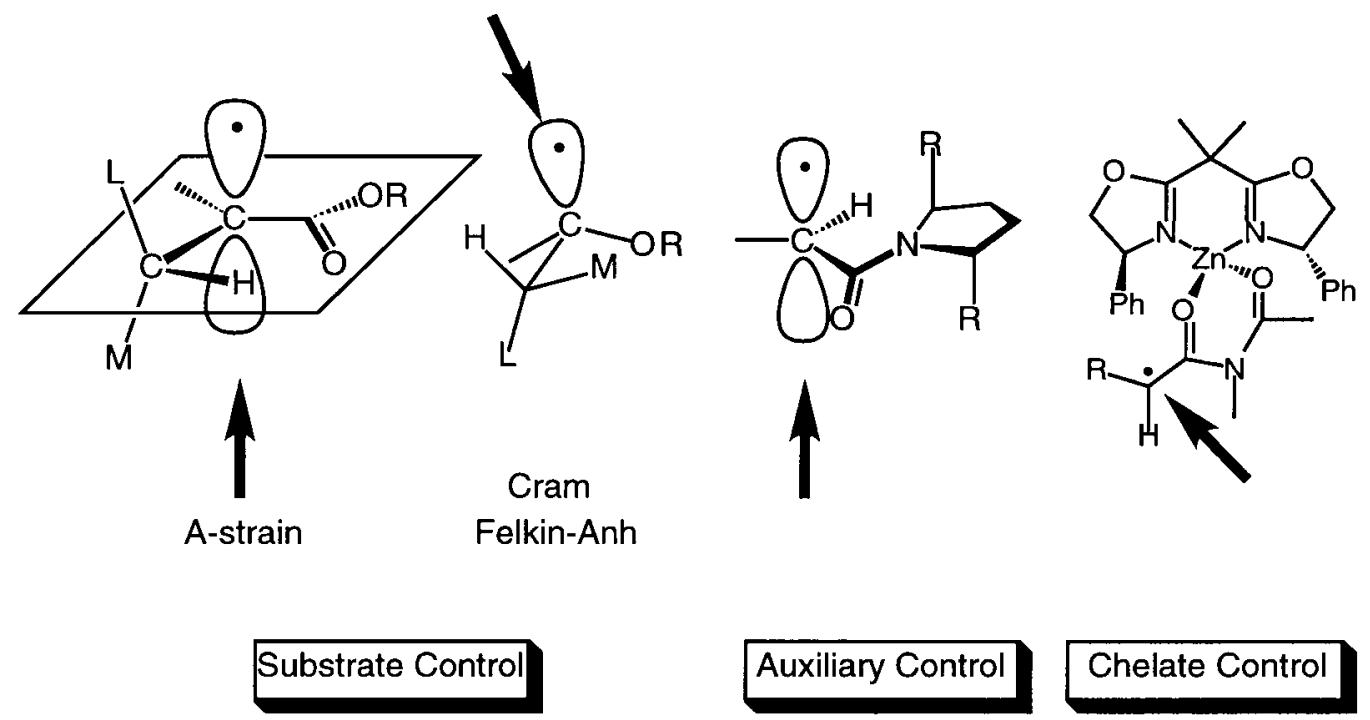

$$
\text { Auxiliary Control }
$$

Chelate Control

Fig. 1 Preferred and reactive conformations of acyclic radicals leading to stereoselective reactions.

However, for reactions between two radicals, which occur with diffusion-controlled rates, one cannot expect that substituents induce stereoselectivity. We have now shown that this changes in reactions of photolytically generated biradicals: Both the singlet and the triplet biradicals can react with high stereoselectivity, but the outcome of the reactions depends upon the multiplicity of the biradical.

*Lecture presented at the $13^{\text {th }}$ International Conference on Organic Synthesis (ICOS-13), Warsaw, Poland, 1-5 July 2000. Other presentations are published in this issue, pp. 1577-1797.

$†$ Corresponding author 
We worked out the rules by studying the photocyclization of acyclic amino acids $\mathbf{1}$ into proline derivatives 3. Intermediate of the reaction is biradical $\mathbf{2}$ formed in intramolecular $\mathrm{H}$-abstraction by the photoexcited carbonyl group [3].<smiles>[X]C(=O)CCN([13CH3])[C@@H]([R])C([Y])=O</smiles>
1<smiles>[X]C(=O)[C@H]([R])N([3H])CCC([X])O</smiles>

2<smiles>[Y]C(=O)C1([R])N([AsH3])[C@H](CC)CC1([Y])O</smiles>

\section{Scheme 1}

In experiments that we have carried out with Pablo Wessig, glycine 4, substituted by a phenyl ketone as photoactive group and $\mathrm{a}_{2}$-symmetrical amine as auxiliary (see 6), photocyclized in $70 \%$ yield and gave diastereomer $\mathbf{5}$ as only detectable proline [4]. Whereas the simple diastereoselectivity could be easily explained by steric and H-bridging effects, the high asymmetric induction was a surprise (Scheme 2).<smiles>[Y6]C(=O)CN([Y6])CCC(=O)c1ccccc1</smiles><smiles>[3H]N(CCC(O)c1ccccc1)CC(=O)N1[C@H]2CO[C@@H](P)O[C@H]2[C@H]2O[C@H](P)OC[C@H]21</smiles>

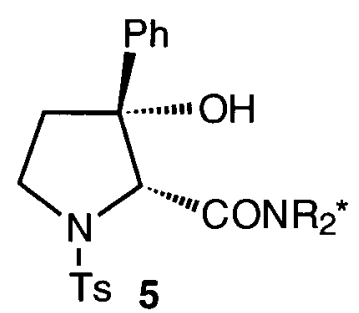

$70 \%,>30: 1$

\section{Scheme 2}

Photocyclization of selectively deuterated glycine derivative 7 lead to the $2 R$-glycine $\mathbf{8}$ for both $\mathrm{H}$ - and D-abstraction. Thus, the formation of the biradical does not influence the stereochemical outcome of the reaction. It is the C,C-bond formation of biradical 9 that determines the stereochemistry (Scheme 3). 


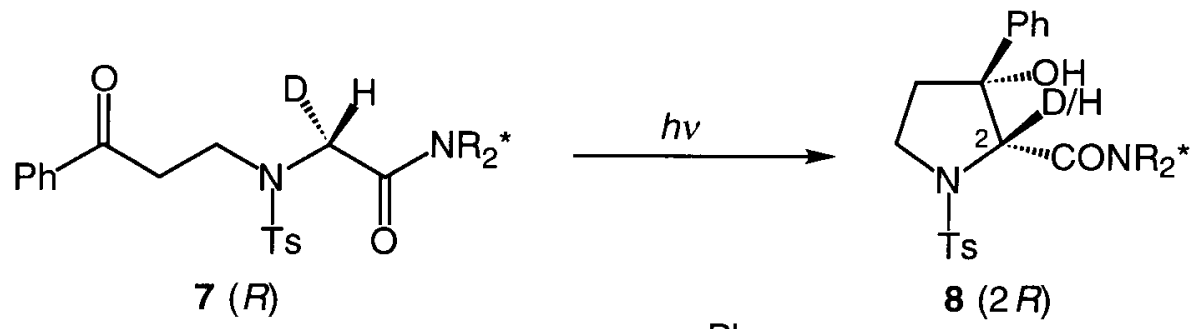

\section{Re face attack}<smiles>[2H]C1(C(=O)N2C3COC(c4ccccc4)OC3[C@@H]3O[C@H](c4ccccc4)OC[C@H]32)CC[C@@H](P)C1(O)P</smiles>

Scheme 3

Obviously, the lifetime of the intermediate biradical is so long that a conformation like $\mathbf{9}$ can be adopted where the benzyl radical attacks the glycinyl radical from the less-shielded side. In order to understand the long lifetime of the biradical, we carried out reactions in the presence of naphthalene as quencher of the triplet ketone. Under these conditions no cyclization occurred. Thus, the photocyclization of 7 occurred via a triplet ketone and therefore, via a triplet biradical that cannot directly cyclize and thus has a relatively long lifetime. In order to cyclize, this triplet biradical has to undergo a tripletsinglet interconversion. This reaction occurs via a partial overlap of the radical orbitals, which brings the radical carbon centers close to each other and is therefore influenced by the chiral auxiliary (Scheme 3). The singlet biradical then cyclizes rapidly as will be demonstrated with ketoesters.<smiles>[R]C(C)[C@H](C)OC(C)=O</smiles>

10<smiles>CC(=O)[C@H](P)N1CC[C@](O)(c2ccccc2)[C@H](NC(=O)OCc2ccccc2)C1=O</smiles>

11

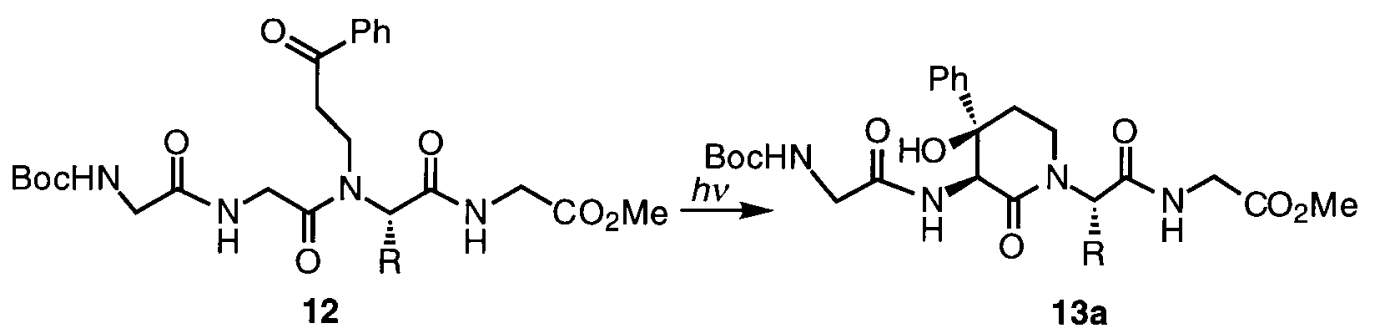

Scheme 4

(C) 2000 IUPAC, Pure and Applied Chemistry 72, 1623-1629 


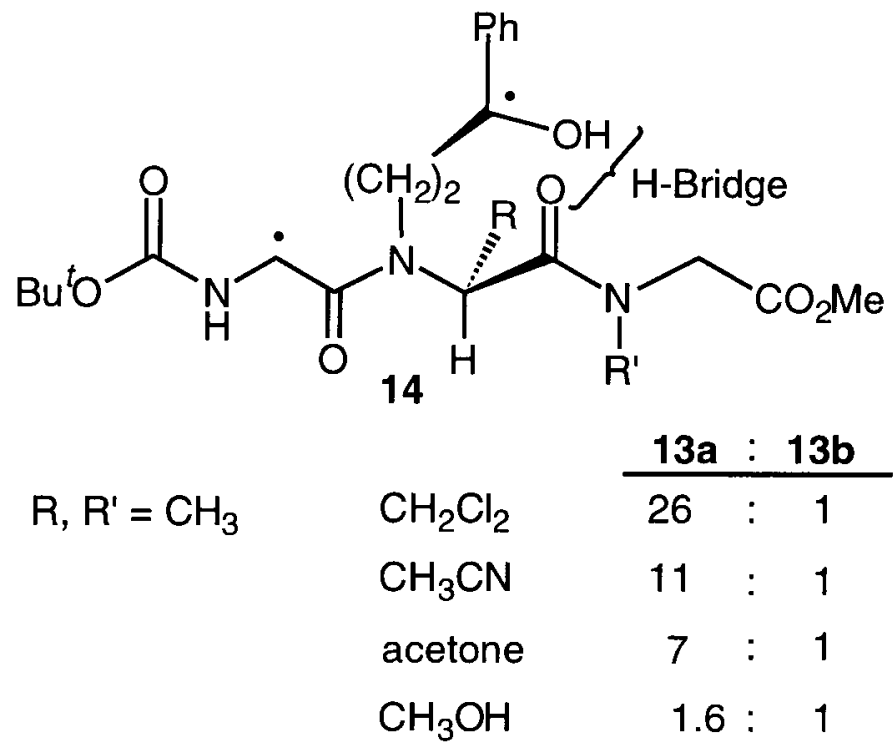

Fig. 2 Preferred conformation of biradical 14 and solvent influence on the diastereoselectivity 13a:13b. In 13b the configuration of both RCONH- and HO- substituents are opposite to that of 13a.

In peptides, asymmetry can be induced by the stereogenic centers of the amino acids. Thus, substituted dipeptide 10 (Scheme 4) yielded with high regioselectivity (6- versus 5-membered ring), high simple diastereoselectivity (cis versus trans), and also remarkable asymmetric induction lactone $\mathbf{1 1}$ as major photoproduct [5].

The regioselectivity could be explained by the preferred conformation of $\mathbf{1 0}$ where the A-strain forced the substituted amino acid to adopt a conformation that is not favorable for an intramolecular $\mathrm{H}$ abstraction by the photoexcited phenyl ketone. The cis orientation of the $\mathrm{OH}-$ and NHBoc-groups is presumably caused by H-bridges, because in solvents that break these intramolecular H-bridges, the selectivity disappeared. H-bridges are presumably also the reason for the chiral induction. We deduced this from experiments with tetrapeptide 12, which reacted with very similar regioselectivity and simple diastereoselectivity, but the asymmetric induction in the formation of 13a was opposite to that of $\mathbf{1 1}$ (Scheme 4). Ab initio calculations demonstrated that in triplet biradical 14 (Fig. 2) the OH-group of the benzyl radical forms a H-bond with the amide group of the peptide. This brings the radical to the front side and explains the cyclization from this side leading to 13a. Solvents that break the intramolecular $\mathrm{H}$-bridges destroy the asymmetric induction. In dipeptides like $\mathbf{1 0}$ the $\mathrm{H}$-bridge from the backside to the NHBoc-group is preferred.<smiles>COC(=O)C([14CH3])N([13CH3])CCC(=O)c1ccccc1</smiles>

15

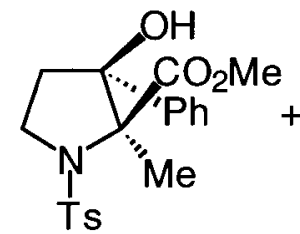

$16 a$

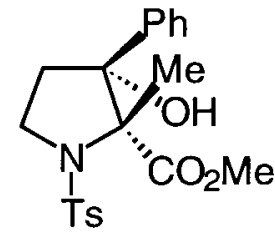

$16 b$

$55 \quad: \quad 45$ 


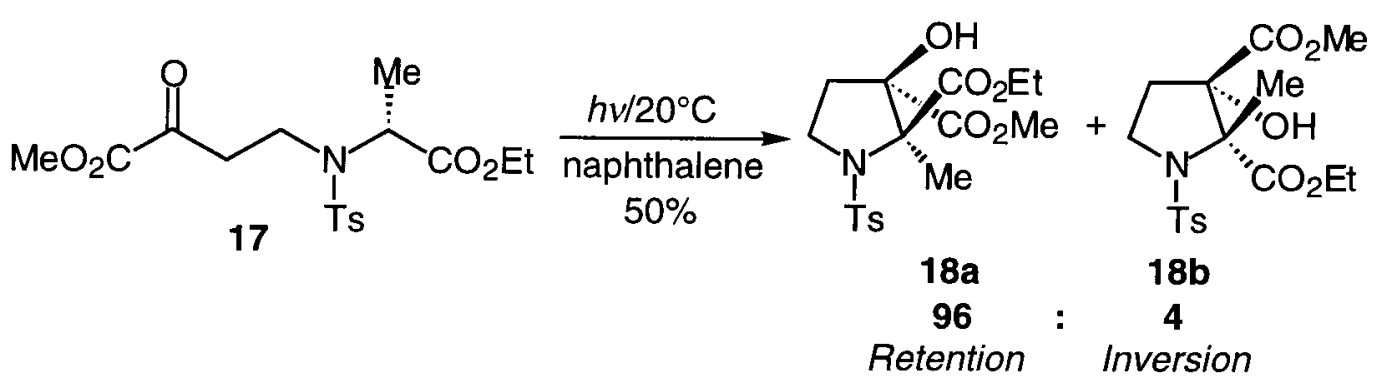

Scheme 5

Next, we checked what happens in cases where the C,C-bond formation occurs in the stereogenic center of an amino acid (Scheme 5). We expected that during photocyclization of alanine derivatives, the information of the chiral center of the alanine would be lost because of the long lifetime of the intermediate triplet biradical. This was indeed the case in reactions with $\mathbf{1 5}$ but the situation changed dramatically when ketoester $\mathbf{1 7}$ was used (Scheme 6). In the presence of the triplet quencher naphthalene, the reaction occurred with a high retention at the stereogenic center of the amino acid [6].

The high retention of configuration in the photocyclization of the ketoester $\mathbf{1 7}$ shows that the intermediate biradical 19 has a memory of chirality [7].<smiles>[3H]N(CCO[C@@H](C)[C@@H](C)COCC)C(C)C</smiles>

17

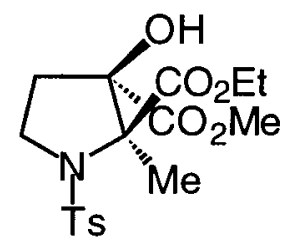

18

$92 \%$ ee<smiles>CCOC(=O)C(C)N(CCC(O)C(C)=O)C(C)=O</smiles>

Scheme 6

This memory effect can easily be explained by conformation 20a (Fig. 3) that is formed in the Habstraction step by the ketoester group of $\mathbf{1 7}$. Because the lifetime of the $S_{1}$ state of naphthalene is about $100 \mathrm{~ns}$, the kinetic and thermodynamic parameters make a singlet energy transfer from the photoexcited naphthalene to the $S_{1}$ state of ketoester 17 possible [8]. This singlet ketoester reacts to the cyclized 
product 18a. The major amount is transferred to the $T_{1}$ state of $\mathbf{1 7}$ that is then trapped by naphthalene. On the way from educt 17 , via singlet biradical 20 a to product $18 \mathrm{a}$, the central chirality of $\mathbf{1 7}$ is converted into a helical chirality of $\mathbf{2 0 a}$. The racemization of singlet biradicals $20 \mathbf{a} \rightleftharpoons \mathbf{2 0 b}$ by rotation around C,C-single bonds is considerably slower than the cyclization of the singlet biradical $(\mathbf{2 0 a} \rightarrow$ 18a). This leads to the observed memory effect of chirality.

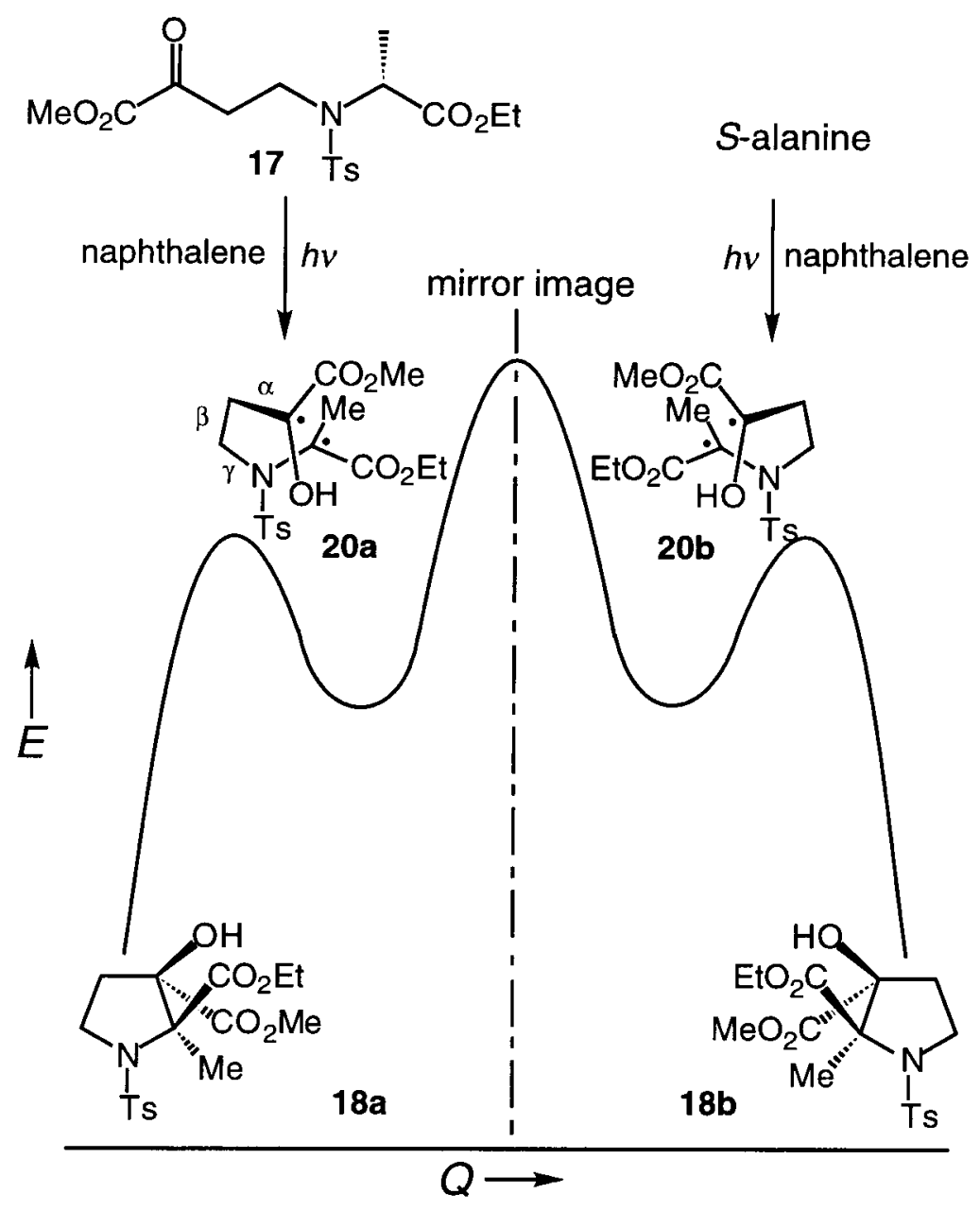

Fig. 3 Energy profile diagram for the racemization and cyclization of singlet biradicals $\mathbf{2 0 a}$ and $\mathbf{2 0 b}$.

\section{CONCLUSION}

Photochemical cyclization experiments of glycine derivatives demonstrate that the stereoselective intramolecular C,C-bond formation of a biradical can be governed a) by asymmetric induction if the reaction occurs via a triplet biradical, and $b$ ) by a memory effect if triplet biradicals are not intermediates on the pathway leading to the reaction products (Scheme 7).

(C) 2000 IUPAC, Pure and Applied Chemistry 72, 1623-1629 


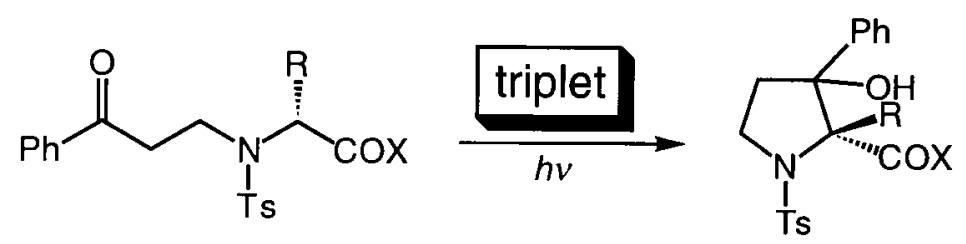

$$
\begin{array}{lcl}
\hline R=H, X=N R_{2}^{*} & >30 & \text { asymmetric induction } \\
R=\mathrm{Me}, \mathrm{X}=\mathrm{OEt} & 1.2 & \text { memory effect }
\end{array}
$$<smiles>[X]C(=O)C([R])N([13CH3])CCC(=O)OC</smiles>

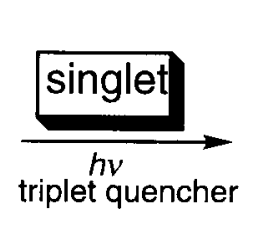

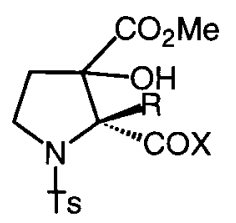

\begin{tabular}{lll|}
$R=H, X=N_{2}{ }^{*}$ & 0.5 & asymmetric induction \\
\hline$R=\mathrm{Me}, \mathrm{X}=\mathrm{OEt}$ & 25 & memory effect \\
\hline
\end{tabular}

Scheme 7

\section{ACKNOWLEDGMENTS}

This work was supported by the Swiss National Science Foundation.

\section{REFERENCES}

1. B. Giese. Radicals in Organic Synthesis: Formation of Carbon-Carbon Bonds, Pergamon Press, Oxford (1986).

2. D. P. Curran, N. A. Porter, B. Giese. Stereochemistry of Radicals Reactions, VCH, Weinheim (1996).

3. K. Walther, U. Kranz, H.-G. Henning. J. Prakt. Chem. 323, 859 (1987).

4. P. Wessig, P. Wettstein, B. Giese, M. Neuburger, M. Zehnder. Helv. Chim. Acta 77, 829 (1994).

5. C. Wyss, R. Batra, C. Lehmann, S. Sauer, B. Giese. Angew. Chem. Int. Ed. Engl. 35, 2529 (1996).

6. B. Giese, P. Wettstein, C. Stähelin, F. Barbosa, M. Neuburger, M. Zehnder, P. Wessig. Angew. Chem. Int. Ed. Engl. 38, 2586 (1999).

7. The term memory of chirality is used here with the meaning that was proposed in: K. Fuji and T. Kawabata. Chem. Eur. J. 4, 169 (1998).

8. P. J. Wagner. Mol. Photochem. 3, 169 (1971). 